\title{
Update of the epidemiological distribution of COVID-19 variants: a review article
}

\author{
Thomás Cavalcanti Pires de Azevedo ${ }^{1}\left[\right.$, Vanessa Santos Cavalcante Melo ${ }^{1}$, \\ Renata Maciel da Silva ${ }^{1}$, Beatriz Guerra de Holanda Barbosa ${ }^{1}$ (D), \\ Lucas Zloccowick de Melo Christofoletti ${ }^{~(1)}$, Giovanna Maria Correia Silva do Nascimento ${ }^{1}$ (), \\ Guilherme Santos Lins de Oliveira' (1), Fabiano Timbó Barbosa ${ }^{1,2,3}$ (D), \\ Célio Fernando de Sousa-Rodrigues ${ }^{1,2,4}$ (1), Fernando Wagner da Silva Ramos ${ }^{1,4,5}$
}

\section{INTRODUCTION}

The severe acute respiratory syndrome coronavirus 2 (SARS$\mathrm{CoV}-2)$ resulted in the current pandemic that has spread since 2019, being the virus responsible for the "Coronavirus Disease 2019" (COVID-19) ${ }^{1}$. This disease was responsible for more than 171,708,011 infections worldwide, until June 7, 2021, and more than 3,697,151 deaths. Concomitantly, with the development of vaccines, about 447,911,020 human beings have been vaccinated and more than 2,049,141,878 doses have been applied, in accordance with World Health Organization (WHO) ${ }^{2}$.

Viruses are known to have the ability to constantly mutate in such a way that they give rise to variants that persist for a long time or disappear in a short period of time. During the pandemic, several countries recorded these events ${ }^{3}$. In this context, the WHO is working on a global surveillance system so that all countries can collaborate with new information on variants of SARS-CoV-2 ${ }^{4}$.

Scientific teams are studying the range of circulation of these new variants, the effect that these mutations can have on potential reinfection, diagnosis, vaccination, severity, and disease transmission. Countries are working with the WHO on how surveillance systems can be strengthened or adapted to assess the potential variations of the virus through continuous systematic clinical and epidemiological surveillance, establishing genetic sequencing when possible and accessing international findings to send sequencing samples and phylogenetic analysis 5 .

The pandemic spread of a virus in virgin populations can select mutations that alter pathogenesis, virulence, and/ or transmissibility. The ancestral form of SARS-CoV-2 that emerged from China has now been largely replaced by strains containing the D614G mutation, replacement of aspartic acid with glycine (Asp 614-para-Gly) in the viral spike protein. However, this change in the virus seems to have evolved into greater transmissibility in humans, rather than greater pathogenicity, due to the association with higher viral loads in the upper respiratory tract than those observed with the ancestral strain ${ }^{6-9}$.

As of May 25, 2021, there are four variants of concern to WHO around the world: South Africa (B.1.351, May 2020), United Kingdom (B.1.1.7, Sep 2020), India (B.1.617, Oct 2020), and Brazil (P.1, Nov 2020) ${ }^{10}$.

Thus, the purpose of this study is to describe the geographic distribution of the most worrying variants of COVID-19.

\section{METHODS}

The present review was performed in MEDLINE (PubMed) and LILACS, following the recommendations of the Preferred

\footnotetext{
${ }^{1}$ Centro de Estudos Superiores de Maceió - Maceio (AL), Brazil.

${ }^{2}$ Universidade Federal de Alagoas - Maceio (AL), Brazil.

${ }^{3}$ Hospital Geral do Estado de Alagoas - Maceio (AL), Brazil.

${ }^{4}$ Universidade Estadual de Ciências da Saúde de Alagoas - Maceio (AL), Brazil.

${ }^{5}$ Secretaria Municipal de Saúde - Maceio (AL), Brazil.

*Corresponding author: nandobiomedico@hotmail.com

Conflicts of interest: the authors declare there are no conflicts of interest. Funding: none.

Received on June 29, 2021. Accepted on July 28, 2021.
} 
Reporting Items for Systematic Reviews and Meta-Analyses (PRISMA $)^{11}$. The search terms used were SARS-CoV-2, COVID-19, and variants to find articles published until June 7,2021 . The exclusion criteria were inappropriate topics or not relevant to the purpose of the study (Figure 1).

\section{Genomic sequencing}

Since the start of the pandemic in 2020, global science has relentlessly sought to encode the genetic sequence of SARSCoV-2 to advance vaccine development. Concomitantly, it was noticed, in some countries around the world, that the genomes of the viruses that infect some human beings had some differences from the genome of the new coronavirus responsible for the COVID-19 pandemic. In a study published in April 2020, the genomic sequences of Italian, Chinese, Mexican, German, and Australian patients were compared, reaching the conclusion that not all sequences belonged to the same viral strain ${ }^{12}$.

In another phylogenetic study with 160 SARS-CoV-2 genomes collected from different regions of the world, it was verified that the existence of three central variants differ mainly by protein alterations ${ }^{13}$. Therefore, the genome of the new coronavirus is very subject to mutations, favoring the difficulty in the production of antibodies and the recognition of the immune system against the viral antigen ${ }^{14}$.

Much of this mutant capacity of SARS-CoV-2 is associated with the Spike receptor-binding domain (RBD), especially in the region of the Spike glycoprotein that regulates virus binding at the angiotensin-converting enzyme 2

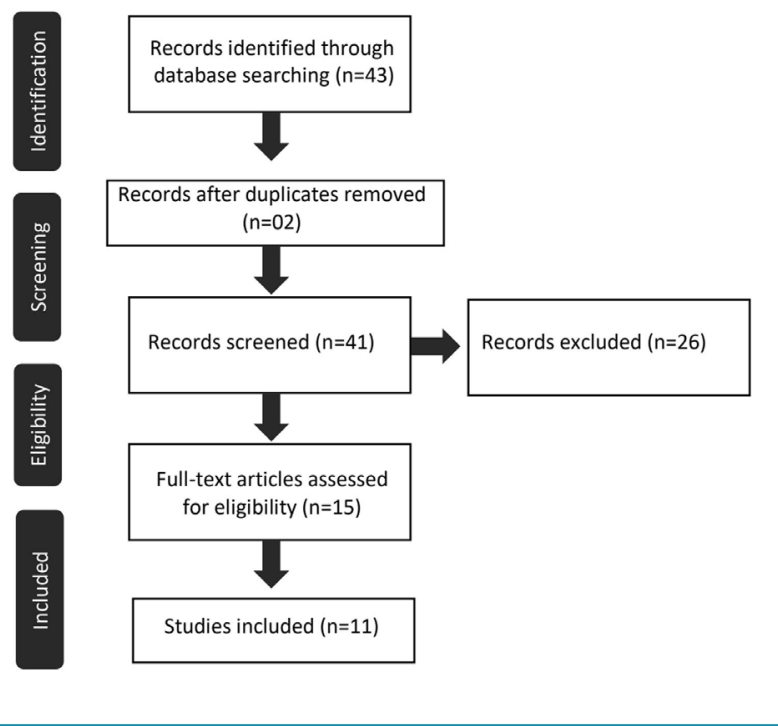

Figure 1. Flow chart to demonstrate the search strategy.
(ACE2) receptor that remains located on the surface of human cells ${ }^{15}$.

The D614G substitution increases the replication ability of SARS-CoV-2 in primary epithelial cells, with an advantage in the upper respiratory tract epithelial cells in nasal and large (proximal) epitheliums of the airways that express greater amounts of human ACE2 (hACE2) receiver ${ }^{6-8}$. In addition, Korber et al. ${ }^{9}$ concluded that the D614G substitution does not significantly change the morphology of SARS-CoV-2, the peak cleavage pattern, and the in vitro neutralization properties in the context of the live virus.

\section{Viral variants}

According to the WHO, SARS-CoV-2 variants can be divided into variants of interest (VOIs) and variants of concern (VOCs). As of June 1, 2021, there are four variants of concern, and they are found in the UK, South Africa, Brazil, and India. Regarding the VOIs, six were documented ${ }^{16}$ (Table 1).

The variant B.1.1.7 contains eight mutations in Spike, and the strain is associated with many additional mutations throughout the SARS-CoV-2 genome. Among the Spike mutations, N501Y is suggested to increase the ACE2-RBD interaction. Double deletion of H69-V70 amino acids in Spike's $\mathrm{N}$-terminal domain (NTD) often co-occurs with one of the three mutations in RBD: N501Y, N439K, or Y453F. Y453F is associated with an outbreak in Denmark, with and without the presence of a $\Delta \mathrm{H} 69 / \mathrm{V} 70$ deletion, but is also found in people in the UK. The N439K mutation usually occurs with $\Delta \mathrm{H} 69 / \mathrm{V} 70$, but it also frequently occurs without the $\Delta \mathrm{H} 69 /$ V70 mutation. In an in vitro selection study with Regeneron antibodies, Y453F and N439K were found to escape neutralization by REGN10933 and REGN10987 that comprise the REGN-COV2 cocktail regime. It has also been reported that N439K resists neutralization while maintaining the virus' fitness /infectivity. Another mutation of obvious concern in B.1.1.7 is $\mathrm{P} 681 \mathrm{H}$, proximal to the furin cleavage site that has often appeared independently and has come to dominate the local epidemic in Hawaii ${ }^{17-19}$.

A new strain of SARS-CoV-2 has been discovered in South Africa, 501Y.V2, which is composed of nine alterations in the Spike protein. However, although this new strain is associated with greater transmissibility and not immunogenicity, it is known that the accumulation of mutations can result in a space for viral neutralization. The nine alterations in the Spike protein can be divided into groups that include four protein substitutions and a deletion (L18F, D80A, D215G, $4242-244$, and R246I) ${ }^{20}$. In Brazil, viral mutations were also found in this same region of the Spike protein ${ }^{21}$. 
Table 1. SARS-CoV-2 VOCs and VOls, as of June 1, 2021.

\begin{tabular}{|c|c|c|c|}
\hline Pango lineage & First detected in & $\begin{array}{l}\text { Earliest } \\
\text { samples }\end{array}$ & Characteristic spike mutations \\
\hline \multicolumn{4}{|c|}{ Variants of concern (VOCs) } \\
\hline B.1.1.7 & United Kingdom & Sep 2020 & $\begin{array}{l}\text { 69/70del, 144del, N501Y, A570D, D614G, } \\
\text { P681H, T716l, S982A, D1118H }\end{array}$ \\
\hline B.1.351 & South Africa & May 2020 & $\begin{array}{l}\text { D80A, D215G, 241/243del, K417N, } \\
\text { E484K, N501Y, D614G, A701V }\end{array}$ \\
\hline P.1 & Brazil & Nov 2020 & $\begin{array}{l}\text { L18F, T20N, P26S, D138Y, R190S, K417T, E484K, } \\
\text { N501Y, D614G H655Y, T1027I, V1176F }\end{array}$ \\
\hline B.1.617.2 & India & Oct 2020 & $\begin{array}{l}\text { L452R, D614G, P681R, } \pm(E 484 Q, Q 107 H \\
\text { T19R, del 157/158, T478K, D950N) }\end{array}$ \\
\hline \multicolumn{4}{|c|}{ Variants of interest (VOIs) } \\
\hline B.1.427/B.1.429 & United States of America & Mar 2020 & S13I, W152C, L452R, D614G \\
\hline P.2 & Brazil & Apr 2020 & E484K, D614G, V1176F \\
\hline B. 1.525 & Multiple countries & Dec 2020 & Q52R, A67V, 69/70del, 144del, E484K, D614G, Q677H, F888L \\
\hline P.3 & Philippines & Jan 2021 & $\begin{array}{l}\text { 141/143del, E484K, N501Y, D614G, } \\
\text { P681H, E1092K, H1101Y, V1176F }\end{array}$ \\
\hline B.1.526 & United States of America & Nov 2020 & L5F, T95I, D253G, D614G, A701V, + (E484K or S477N) \\
\hline B.1.616 & France & Feb 2021 & $\begin{array}{l}\text { H66D, G142V, 144del, D215G, V483A, } \\
\text { D614G, H655Y, G669S, Q949R, N1187D }\end{array}$ \\
\hline
\end{tabular}

Source: World Health Organization. COVID-19 Weekly Epidemiological Update. Edition 41, published 25 May 2021.

\section{CONCLUSION}

This review showed that much of this mutated capacity of SARS-CoV-2 is associated with the Spike RBD that regulates virus binding to the angiotensin- 2 converting enzyme receptor (ACE2). The VOCs to WHO detected so far (June 7, 2021) have been mapped in the UK, South Africa, Brazil, and India. It is known that they are more associated with greater transmissibility than pathogenicity. However, there is still a need for further studies to identify whether current vaccines will be effective in inducing antibody production against the variants and whether such variants will be responsible for new waves of infection in the current pandemic.

\section{AUTHORS" CONTRIBUTIONS}

TCPA: Data curation, Writing - original draft, Writing - review \& editing. VSCM: Data Curation, Writing - original draft, Writing - review \& editing. RMS: Data Curation, Writing - original draft, Writing - review \& editing. BGHB: Data Curation, Writing original draft, Writing - review \& editing. LZMC: Data Curation, Writing - original draft, Writing - review \& editing. GMCSN: Data Curation, Writing - original draft, Writing - review \& editing. GSLO: Data Curation, Writing - original draft, Writing - review \& editing. FWSR: Methodology, Writing - original draft, Writing - review \& editing. CFSR: Methodology, Writing - original draft, Writing - review \& editing. FTB: Methodology, Writing - original draft, Writing - review \& editing.

\section{REFERENCES}

1. Van der Made $\mathrm{Cl}$, Simons A, Schuurs-Hoeijmakers J, Van den Heuvel G, Mantere T, Kersten S, et al. Presence of genetic variants among young men with severe COVID-19. JAMA. 2020;324(7):663-73. https://doi.org/10.1001/jama.2020.13719

2. World Health Organization. WHO Coronavirus (COVID-19) Dashboard [internet]. Geneva: World Health Organization; 2021. [cited on Jun. 4, 2021].
Available from: https://covid19. who.int/?gclid=EAlalQo bChMI6LCVUYX08AIVyICRCh32EQ2HEAAYASABEgLAhfD_BwE

3. Centers for Disease Control and Prevention. New variants of the virus that causes COVID-19 [internet]. Atlanta: Centers for Disease Control and Prevention; 2021. [cited on Feb. 12, 2021]. Availabe from: https://www.cdc.gov/coronavirus/2019ncov/transmission/variant.html 
4. Mahase E. Covid-19: what new variants are emerging and how are they being investigated? BMJ. 2021;372:n158. https:// doi.org/10.1136/bmj.n158

5. World Health Organization. SARS-sob-2 Variants [internet]. Disease Outbreak News; 2020. Geneva: World Health Organization; 2021. [cited on Feb. 12, 2021]. Available from: https://www.who.int/csr/don/31-december-2020-sars-cov2variants/en/

6. Hou YJ, Chiba S, Halfmann P, Ehre C, Kuroda M, Dinnon KH 3rd, et al. SARS-CoV-2 D614G variant exhibits efficient replication ex vivo and transmission in vivo. Science. 2020;370(6523):1464-8. https://doi.org/10.1126/science.abe8499

7. Yurkovetskiy L, Wang X, Pascal KE, Tomkins-Tinch C, Nyalile T, Wang Y, et al. Structural and functional analysis of the D614G SARS-CoV-2 spike protein variant. Cell. 2020;183(3):739-51. e8. https://doi.org/10.1016/j.cell.2020.09.032

8. Hodcroft EB, Zuber M, Nadeau S, Vaughan TG, Crawford KHD, et al. Spread of a SARS-CoV-2 variant through Europe in the summer of 2020. Nature. 2021;595(7869):707-12. https://doi.org/10.1038/s41586-021-03677-y

9. Korber B, Fischer WM, Gnanakaran S, Yoon H, Theiler J, Abfalterer $W$, et al. Tracking changes in SARS-CoV-2 spike: evidence that D614G increases infectivity of the COVID-19 virus. Cell. 2020;182(4):812-27.e19. https://doi.org/10.1016/j. cell.2020.06.043

10. World Health Organization. COVID-19 Weekly epidemiological update [internet]. Edition 41; 2021. Geneva: World Health Organization; 2021. [cited on May 25, 2021]. Available from: https://apps.who.int/iris/handle/10665/341525

11. Moher $D$, Shamseer $L$, Clarke $M$, et al. Preferred reporting items for systematic review and meta-analysis protocols (PRISMA-P) 2015 statement. Syst Rev. 2015;4(1):1. https:// doi.org/10.1186/2046-4053-4-1

12. Stefanelli P, Faggioni G, Lo Presti A, Fiore S, Marchi A, Benedetti $E$, et al. Whole genome and phylogenetic analysis of two SARS-CoV-2 strains isolated in Italy in January and February 2020: additional clues on multiple introductions and further circulation in Europe. Euro Surveill.
2020;25(13):2000305. https://doi.org/10.2807/1560-7917. ES.2020.25.13.2000305

13. Forster P, Forster L, Renfrew C, Forster M. Phylogenetic network analysis of SARS-CoV-2 genomes. Proc Natl Acad Sci U S A. 2020;117(17):9241-3. https://doi.org/10.1073/ pnas.2004999117

14. Koyama T, Weeraratne D, Snowdon JL, Parida L. Emergence of drift variants that may affect COVID-19 vaccine development and antibody treatment. Pathogens. 2020;9(5):324. https:// doi.org/10.3390/pathogens9050324

15. Santos JC, Passos GA. The high infectivity of SARS-CoV-2 B.1.1.7 is associated with increased interaction force between Spike-ACE2 caused by the viral N501Y mutation. bioRxiv. 2021;12.29.424708. https://doi.org/10.1101/2020.12.29.424708

16. World Health Organization. COVID-19 Weekly epidemiological update. Edition 42; 2021. Geneva: World Health Organization; 2021. [cited on Jun 1, 2021]. Available from: https://apps. who.int/iris/handle/10665/341525.

17. Shen X, Tang H, McDanal C, Wagh K, Fischer W, Theiler J, et al. SARS-CoV-2 variant B.1.1.7 is susceptible to neutralizing antibodies elicited by ancestral spike vaccines. Cell Host Microbe. 2021;29(4):529-39.e3. https://doi.org/10.1016/j. chom.2021.03.002

18. Koyama T, Weeraratne D, Snowdon JL, Parida L. Emergence of drift variants that may affect COVID-19 vaccine development and antibody treatment. Pathogens. 2020;9(5):324. https:// doi.org/10.3390/pathogens9050324

19. Koyama T, Platt D, Parida L. Variant analysis of SARS-CoV-2 genomes. Bull World Health Organ. 2020;98(7):495-504. https://doi.org/10.2471/BLT.20.253591

20. Wibmer $C K$, Ayres F, Hermanus T, Madzivhandila M, Kgagudi $P$ Oosthuysen B, et al. SARS-CoV-2 501Y.V2 escapes neutralization by South African COVID-19 donor plasma. Nat Med. 2021;27(4):622-5. https://doi.org/10.1038/s41591-021-01285-x

21. McCallum M, Marco A, Lempp F, Tortorici MA, Pinto D, Walls $A C$, et al. N-terminal domain antigenic mapping reveals a site of vulnerability for SARS-CoV-2. Cell. 2021;184(9):2332-47. e16. https://doi.org/10.1101/2021.01.14.426475 